\title{
Research Methodology in Adult Learning and Education
}

Paolo FEDERIGHI•

\begin{abstract}
Consent in the definition of adult education is only apparent and circumscribed. Substantial differences survive, fueled by various national ideologies, cultures and policies. The plurality of angles determines a multiplicity of research approaches. Transformative research is the typical model of adult education research and is analysed in its core components. Its peculiarity is the property of ensuring immediate production not only of knowledge, but of change processes. This property has favoured proliferation especially outside the academic community of education sciences. The process was guided by the users of the research, i.e. by those who have roles and resources that enable them to orientate the research in response to personal and organisational needs. This phenomenon necessarily produces a process of social construction of the meaning and the methodological content of the research. This expansion urges the development of a transformative research that also attributes to the education proletariat the role of inspiration and guidance in adult education.
\end{abstract}

\section{The object of research in adult education}

Research in adult education has its own specificity that varies according to research goals. We may have researches that primarily aim at exercising forms of control over on-going educational processes, or interested in understanding and interpreting educational phenomena, or ultimately in modifying the educational conditions of the population. These three options involve not only a different conception of how to do research. They are also based on different definitions of the subject of study: adult education.

Their identification can be made taking into account both the major traditions of second logic research and the representations of the object identifiable in the research. On this basis, we can distinguish between three different approaches:

- the institutional and organisational definition, both public and private

- the phenomenal definition, which is concerned with the study of educational behaviours in adulthood

- the transformative definition, designed to highlight the meaning, the reason for being, the social function of adult education.

The institutional definition orients the researcher's observation towards the historical forms in which the adult education system of a country or organisation

\footnotetext{
- Paolo Federighi - Professor, DHC, Department of education and Psychology

University of Florence paolo.federighi@unifi.it
} 
has materialised. It is therefore exposed to constant changes in the policies of governments in office. It is the result of complex historical processes of economic, social and political negotiation and is constantly exposed to changes and reforms, not necessarily improving. The reading and comparability of institutionalised adult education has been supported and influenced by the introduction of international education classification systems. Starting in 1958, UNESCO began to work systematically on the definition of ISCED-International Standards Classification on Education (Godin, 2005).

The institutional definition of adult education has the inherent limitation of restricting its point of view to products, systems, programmes generated by public policies, and private and non-private companies. It is, on the other hand, constantly exposed to changing the equilibrium of educational power and therefore exposed to evolutionary/involuntive dynamics dictated by the desires of power and its evaluations of opportunities rather than rationality. As Rubenson remembers: "The Bourdieusian perspective suggests that the evolving configuration of adult education research is directly impacted by changes to the internal structures of the field as such as well as by changes to the social context of the field, such as the social and economic role awarded to adult learning and education by the policy community" (Rubenson, 2015: 126). The dependence of the institutional dimension on the dynamics of power is made even more evident by the main function of the policies and systems of organisations: to determine what's up to who. We refer to the distribution function. It is not enough to point out the "social and economic role given to adult learning" as the problem of distributive justice arises the moment that this happens: what opportunities for which people. The arbitrariness of educational powers has a positive or negative influence on the institutional definition of adult education.

However, the importance of the public and private policy-making distributive function makes sense of the reason that drives part of the research world to focus mainly on this dimension of adult education. Systemic and organisational architectures, management and control of their dynamics, determination of policy measures and anticipation of the effects of the changes introduced are the focus of this first approach.

The phenomenal definition of adult education orientates the researcher's observation towards the educational processes that act in the everyday life of individuals. It is therefore focused on the description and study of the different types of educational actions and the transactions between the subject and the environment through which new knowledge is produced. This definition has had the merit of urging the researcher into studying experience as a source of learning and recognising and considering the difference between formal education, non formal education and informal education. This has consented the theory and the search to attribute meaning and educational functions not only to training systems but also to educational processes that act in daily life and work. Moreover, the phenomenal definition has prompted research to understand and generate the many training devices, the mechanisms through 
which we can intentionally structure the educational actions that determine the value and meaning of the experience itself. All this not only in classrooms, but in workplaces, in cultural institutions, in the family, in cultural and non-cultural consumption.

Research developed in an institutional or phenomenal perspective has helped to understand what works in government institutions and the dynamics present in people's educational processes. However, the study of the efficiency and effectiveness of educational action and policies that generate it does not exhaust the field of adult education. There is more. This type of educational research bases its legitimacy on the difficult bet to produce rules, norms, truths once valid for all, transferable to any context. Educational research that limits its object to the study of the institutional dimension or the peculiarities of educational action can only show what has been possible in certain situations, it can reveal the probable connections between certain actions and their consequences. It is not able to guide educational action in the tortuous meanders of history, though it helps to be more informed.

The transformative definition of adult education reveals the meaning, its reason for being, its function. It is based on a universalistic perspective, identifying in the changing educational conditions of all its own reason of being. At the same time, it roots its own nature and its historical origins in social practice and conscious educational action "not born on the heads of people, but among people, for people, and with people" (De Sanctis, 1988:61).

From the universalist principle, it follows that the sense of research in adult education is directly related to its ability to reduce the rampant education misery. The growing disproportion between those who have the opportunity to acquire future-based skills and those who are not suited to the needs of contemporary economic and social life are evidenced by the results of PISA and PIAAC surveys (which limit their attention to a narrow circle of countries). Disparities are such that, despite the increase in the school population and the costs of training, the ancient skill mismatch and skill shortage phenomenon also accentuates itself in the face of globalisation of the labour market. The mercantilisation of adult education then increases the imbalances in access to formal and non-formal educational opportunities. All this is creating a modern educational proletariat, i.e. subjects forced to not learn what they would need to change their current and future living and working conditions. This is a subject still devoid of its own identity: can we call adult learners those who are on the margins of dynamic learning networks? Those who spent ten years and more of their lives in educational institutions from which they did not receive what they had been promised at the entrance? Words like students, participants appear sarcastic. This is a subject that, in addition to having no name, is incapable of organising itself to change its condition, for the management and the use of existing educational resources in society.

The sense of adult education and its research lies in its specificity of organised practice of people for a widespread growth in the awareness of ongoing educational processes that induce mass miseducation and growing 
educational deprivations (we do not refer to absolute poverty, but to relative poverty: the poor being defined as those who are deprived of the benefits of a modern education and training and therefore do not achieve the standards of skills approachable to the medium to high levels).

The transformative definition assumes the "emancipatory" paradigm perspective. Basil Bernstein has well summed up his perplexities about the possibility of practicing this model by affirming that

"Education cannot compensate for society"(1970). Bernstein's article was lacking in optimism rather than in scepticism. The problem posed by the role of education is exactly the opposite. The problem stems from the role that education plays in contemporary society, the selective and reproductive function that it carries out, and which - not by itself - is the source of the processes of creating the educational misery of our day. The assessments emerging from the European benchmarks on education, from OECD research on school and adult education show a substantial stagnation in the processes of social and educational inclusion. This does not depend solely on the imperfections of education systems and policies. There is no country in the world where the fundamental problems of educational deprivation are solved. No country has a model to export. It is not with policy transfer and with good practices that countries and organisations will improve the performance of education systems. The underlying problem arises from the model that inspires educational systems and policies that support them.

Bourdieu and Passeron explain the phenomenon with the theory of the arbitrariness of educational action: "All pedagogic action is, objectively, symbolic violence insofar as it is the imposition of a cultural arbitrary by an arbitrary power" and they add "pedagogic action seeks to reproduce the cultural arbitrary of the dominant or of the dominant classes"(1977: 5). The transformative approach to adult education identifies the sense of its own research in the emancipation of the deprived from the arbitrary will they are subjected to.

\section{The Limits of Research on Adult Education}

The different perspectives on adult education are translated into different approaches to research that, in this essay, we reduce to two: research on adult education and research in adult education.

We are well aware that with this simplification we leave in the background the reflection on the strengths and weaknesses of positivist and scientific tradition of research for educational research. Likewise, we do not enter directly into the merits of the strengths and weaknesses reflection for educational research of the alternative paradigm, the cluster of approaches that can loosely be termed interpretive, naturalistic, phenomenological, interactionist and ethnographic. Likewise, we keep in the background the reflection on the rise of critical theory as a paradigm in which educational research is conducted. In that regard, we would have little to add to what Louis Cohen, Lawrence Manion and 
Keith Morrison (2007) have already written.

Research on adult education has as its main purpose the description and interpretation of phenomena and educational practices and their evaluation. It is animated essentially by the cognitive objectives of the objects studied, it aims at defining and measuring them in an attempt to predict and control educational dynamics, to understand and interpret them. The distinctive stretch of research on adult education consists of a double splitting:

- between the time of the research and the time of the use of its results and

- between the subjects of the research (the researcher and the subjects observed, studied).

The results of the research on adult education respond to an apparently abstract need for social dynamics and to the academic knowledge of the phenomenon and to the formulation of interpretations and norms. There is no simultaneity among research activity and actions of implementation of the knowledge that it has produced. Similarly, the researcher is placed in a different situation with respect to the actors of the phenomenon studied, they are observed, sometimes inducing them to adopt certain educational behaviours which is then interpreted and evaluated. The researcher is "other" with respect to the social actors in action research, in intervention-research, and participatory research. In fact, the active participation of social actors in the research path does not explicit the social and transformative sense. The main goal seems to be reduced to the methodological one: action, intervention, participation and not the kind of change that one wants to produce with the research.

The two splittings we referred to reveal a profound epistemological weakness. "Since observing means interacting, this precludes the strict validity of the principle of causality", at least in its deterministic interpretation (Heisenberg, 1930). Research cannot avoid the objective limit that prevents the exact identification of the object under analysis. Therefore, it can only produce approximations and not certain data. In our case, we might add that the results produced do not have an educational relevance since research is far from the dynamics it has just observed. For this it may be naive to attribute to the results of research on adult education the ability to describe, interpret and predict every aspect of reality.

The difficulty that research on adult education has is when the study objects 33are observed and measured, is that it is unlikely that the researcher succeeds, alone, in tracing back to the causes of the people's educational behaviour, identifying the deep reasons for the educational dynamics of people, understanding the tension between agency - individual choices and intentions and structure - the contexts and their arbitrary 33and constructive devices.

Similar are the risks of research on adult education when it isolates the subject from the context and considers individuals as constructors of their own actions and isolates it in the world of subjective meanings. The danger of this approach comes from the prevalence of an essentially qualitative method and a micro-pedagogical perspective. Even in this case one forgets "the power of 
external - structural - forces to shape behaviour and events. There is a risk in interpretive approaches that they become hermetically sealed from the world outside the participants' theater of activity - they put artificial boundaries around subjects' behaviour" (Cohen, L., Manion, L., Morrison, K., 2007: 26).

The principle of indetermination introduced by quantum physics results in a drastic re-evaluation of subjectivity in both natural and social investigation. Such a change, far from rejecting any scientific claim, proposes a new way of dealing with adult education research that goes beyond the false contrast between quantitative and qualitative approaches.

The new way originates both from the consideration of the dynamics of power between agency and structure, and from the active role played by research in favour of their liberating development. In other words, adult education and its laws, far from being something objective, to be discovered, are rather constructed by the subject that observes them, the researcher and his ability to position himself in relation to the tension between subjects and contexts.

\section{Research (transformative) in Adult Education}

Research in adult education corresponds to a type of approach that more explicitly than others goes beyond investigation of the cause-effect principle (the causa efficiens, or knowledge of the factor that produced a result), but also questions the End or Purpose (a change or movement's causa finalis, is that for the sake of which a thing is what it is: a seed has the eventual adult plant as its end). Our call to Aristotle's physics and the four forms of cause (causa formalis, materialis, efficiens and finalis object of the scientific inquiry goes through the filter of Heisenberg and his formulation of the principle of indetermination(Heisenberg, 1958). Explaining the causa finalis of adult education forces research and researcher to trace back to why adult education itself exists. This reason is not given once and for all, but it is constantly evolving and object of research. This is a problem that arises whenever research meets a new reality, new subjects, new problems (from research in a jail to that in a bank).

It has been written that research in adult education actually belongs to the current of critical pedagogy and it has been added that "the critical inclination typically comes from researchers identifying themselves with a social cause or movement that leads them to take on the role of spokespersons or judges who unveil the destructive disparity between the ideal and reality (...). Critical pedagogy could thus be expected to appeal to adult education scholars who come from the adult education field, bringing along a desire to conduct research that could help improve practice by focusing on issues of power." (Andreas Fejes and Erik Nylander, 2015: 117-118). These summary considerations do not take into account the specificity of the approach and therefore we consider it appropriate to outline the fundamental features.

Research in adult education is characterised by the special focus on three 
dimensions of research:

- the explication of the causa finalis of the purpose

- attention to the effectiveness of research, i.e. to the changes made to the formal "cause", understood as a change caused by the arrangement, shape or appearance of the thing changing or moving

- the focus on the role of the subject that determines the process of carrying out the research

\section{The purpose of research}

The sense of research in adult education is the very reason why it exists: the reduction of education misery, i.e. supporting the growth processes of those who are today in the conditions of an educational proletariat, in which an increasingly lean formation is reserved. The educational misery of our days lies above all in the phenomena described by all the indicators relating to the inefficiencies of the school and university system, but also from the new and unbridgeable distances that open on various fields: mathematical, scientific, digital, skills that serve today to have a decent job and life, to those that will serve everyone in a few years, when we come out of the Industry 4.0 revolution and enter into Industry 5.0. Educational misery, moreover, and above all, takes into account the quality of informal, natural, unstructured educational processes that work within moments of consumption and daily working.

The definition of the meaning of adult education and research acts both ideologically and culturally. But the bottom line is the balance, the harmony that a principle of distributing equity of growth opportunities creates in society and in production. This balance is not entrusted to the frustrating expectation of total metamorphosis and the denunciation of how far we are from that goal. The principle of fairness is what makes sense to the progressive improvement of educational conditions in work, culture, structured education in the city. It does not diminish the general principles that make up the research framework. It becomes concrete in the identification of concrete and verifiable goals, even measurable, to the realisation of which the research activity is intended to contribute. The challenge of knowing the specific goal that research intends to achieve and its consistency with the raison d'être of adult education is the first feature of adult education research.

\section{The effectiveness of research}

Research in adult education before answering a need for knowledge arises from a need to transform the educational conditions of people. In this sense it is transformative. It does not respond to intellectual curiosity, but to the goals of improving the contexts of life and work and the subjects that live and work in them. It is part of the ways through which to reach the goal that makes sense to the research itself. Other ways will be the economic, organisational, health, urban planning dimension, etc.

Therefore, it is not abstract or disinterested, its value is related to the ability to produce the expected (or unexpected) changes to the present situation. Its 
character, not merely descriptive, exposes its assessment of the added value that it has made. This is not in general terms. The basic criterion for evaluating the effectiveness of transformative research is to measure something like ROEReturn on Equity, or what would not have happened if there was no research input. Compared to the changes that have occurred, what is the added value of the research and what are the changes made by its contribution? This answer includes the evaluation of the meaning of the research carried out.

Transformative research is not a particular method. It is not identified either by qualitative research alone, nor with quantitative nor by other contrasts. It rests on the most appropriate methods and techniques with respect to the research objective. It does not dictate methodological requirements, but - in order to adapt an expression of Feyerabend to our argument - it tends to use "all ideas, all methods, and not just a small selection of them" (Feyerabend, 1975 :295). It does not present itself as "scientific methodology" that can be used to separate science from the rest. Transformative research constitutes a background view of which, inevitably, there are also normal beliefs, myths, religious visions, and so on. The set of these dimensions contributes to the development of its pathways and determines its results. For the same reasons, it is open to methodological pluralism. Transformative research is concerned with the interpretation and use of laws, rules, predictions produced by previous technical research on adult education (Cohen, Manion and Morrison, 2007: 227228). It is also interested in the interpretative methodologies developed in the qualitative approaches. It is open to the use of the results of research methods that seek to clarify, understand and interpret the communications of 'speaking and acting subjects' (Habermas 1974: 8).

Yet it goes beyond the paradigms of adult education research. Transformative research moves from the interest for emancipation of the proletariat of education through reflective action. "The twin intentions of this interest are to expose the operation of power and to bring about social justice as domination and repression act to prevent the full existential realization of individual and social freedoms" (Habermas 1979: 14).

\section{The transformer subject}

A first consequence of the choice of an approach aimed at the dissolution of submergeddeterminants which prevent the development of mass intellectuality is the fact that in transformational research the problem of transferring research results is not the final phase of the research process. Adult education research is educational and therefore initiates processes of educational transformation while research is being conducted. It does not articulate at a time of knowledge followed by one for implementation of the results. Transformation processes associated with research are not limited to the classroom, to the dynamics of a specific training activity: a course, a seminar, etc. The transformation processes to be deployed concern the same reasons that created the need for training: the illiterate does not only pose a literacy problem that deserves an effective and efficient response, but the removal of causes, submergeddeterminants which 
made him illiterate. The real and potential request for adult education, or worse the unexpressed one, is the product of limitations that prevent people from growing, their aspirations to change. In fact, the expression of a request for adult education is not the result of an uninterested aspiration, it is the index of the existence of the will to deal with a problem present in everyday life and work with educational tools. If the question is asked today, it means that in the contexts of life and work there have long been factors and conditions that have not allowed an anticipation of the educational response.

The transformation of these conditions, or of the natural lifelong learning, the causa finalis is underway: the purpose of research in adult education. Such transformations concern both the contexts and the subjects themselves that need to acquire awareness, responsibility and transformative capacity. The realisation of transformative research is based on the ability of the stakeholders to imagine, manage and control the tendency of scientific research processes of the ways in which change is made. This is why transformative research is not limited to the definition of the object and the evaluation of the results of the investigation, it also includes the social organisation of demand for knowledge and change, and the formulation of institutional, financial, and consequent training responses. The researcher does not climb the mountain alone. He shares with the real social actors the power to determine the goals and to manage the research results.

Research in adult education strengthens - presumably - the opportunities to attain the expected changes of the people engaged as it increases the levels of awareness of the management of the social practice in which it operates.

The matter of subjects involved in research and their educational powers is crucial to adult education. The answer, in fact, clarifies who has the power of research orientation, who gets the results, who can decide whether or not to process the process, who evaluates the results.

In hindsight, what we have here called research in adult education or transformative research is a relative novelty. Many policy makers, chairpersons and CEOs of modern companies, public and private executives establish close partnership relationships with the research world, determine desirable goals, methods, desirable transformation processes, evaluation models, and use of results. Through funding projects and programs, researchers are selected and attracted to work for the customers.

The main innovation of transformative research is the ability to structure the path as a program of concerted training actions that lead to the production of knowledge and personal changes and the expected context. The great challenge is to broaden the audience of the subjects who are allowed to use scientifically oriented transformational paths.

\section{The fields of study}

The analysis of the study fields faced by research helps to identify the problems faced by researchers engaged in adult education. In this regard we do 
not go into the merits of the type of research - or into adult education. We limit ourselves to proposing a quick overview to understand its potential and limits.

Starting from the First International Conference on Adult Education (Elsinore, 1949), the researchers' interest in expressing the need for access to scientific production has been progressively manifested in the knowledge and sharing of the common heritage of studies and research. Some scholars have claimed at various times to propose their field classification, in line with their own conception, sometimes transcultural.

In those years where, adult education had not yet found its own stable space within the research centers, this task seemed difficult. The variety of cultures and experiences made it impossible for a serious work of interpretation and classification in a transnational perspective.

Although limited to only English-language production, it is certainly worth recalling the institution, in 1964, by ERIC- "Educational Research Information Center, which in the 1959 "Feasibility Study" was designed as a service that "embraces all educational research and research in other disciplines that have implications for educational theory and practice". International organisations have made an important contribution to the demand for access to research for the production of different cultures and traditions. UNESCO, through the ECLEEuropean Centre for Leisure and Education, was the first to make an outstanding work. In 1977 ECLE started publishing 22 monographs on the organisation and structure of adult education in European countries accompanied by the publication in 1983 of a manual titled "Adult Education in Europe. Methodological Framework for Comparative Studies " (Maydl, 1983). The Monographs often contain the reconstruction of research and adult education developments during the 20th century. In 1994, the UIE-Unesco Institute for Education launched a study to reconstruct the world-wide research landscape (Mauch, 1999).

The results of the two studies agree in providing a highly differentiated framework depending on the cultures of national authors and national policies.

What emerges in particular from the Mauch study is the prevalence of adult education that looks mainly at the inside, which is observed through its publications and its topics such as: quality of learning, global history of adult education, education systems, cultural approaches to adult learning, "New partnerships" with government business, NGOs, civil society development, curriculum development, media and information systems, models for capacity building, theoretical frameworks of adult education and learning (Paul Bélanger, Madeleine Blais, 1999: 276-277).

By way of example, we show below the research classification pattern adopted in the same study for Canada (L'institut canadien d'éducation des adultes, 1999: 188-234):

- Occupational Training in the Classroom and on the Workplace (Relations between Training and Work, Training and Qualification On-the-Job Training Policy, Policy on Vocational Training for Adults

- Literacy (Literacy in Relationships with the Economy and the Workplace; 
Child and Adult Literacy Training; Action Research and Participatory Research;Linguistic and Cultural Aspects,Literacy in the Third World;Policy Analysis)

- Educational Intervention with Adults (Adult Learning, Styles of Learning, Feminist Perspectives in Adult Education, Adult Education and Aboriginal Peoples)

- Prior Learning and Skills Assessment

- Popular Education and Grass-Roots Democracy

- Distance Learning and the Educational Mission of the Media

The panorama that emerges is significant but limited to what the workplace world did in years that still dominated the third industrial revolution and in which the dematerialisation of production, the global value chain and the management of the human factor had not yet entered into the strategies of all countries and businesses.

Systematic mapping exercises carried out 20 years later have adopted more advanced detection methods and technologies, but the results do not seem to be different. We refer to a study that has taken into account "the top-cited articles in three of the leading English-speaking adult education journals between the years 2005-2012 in order to examine whether and in what aspects the field is shaped as heterogeneous and pluralistic. Thus, our analysis aims to provide a description of the field based on what scholars have recognised as worthy to cite" (Fejes, A., Nylander, E. 2015:104). A similar study was proposed by Rubenson in order to "discuss the state of the map of the territory of adult education research. This work is based on a bibliometric analysis and a review of previous articles of a similar nature "(Rubenson, 2015:125).

The results of these studies show, as the authors say, the need to "renew this research field" (Fejes, A., Nylander, E., 2015:121): but in what sense?

The field of research has now exploded to the point that even bibliometric studies can not help us to reconstruct the map. Many studies of great interest and importance are now found in the research programs of medicine, work policies, business and non-business economics, engineering, the sciences of the organization, etc. Rubenson considers this phenomenon the result of a process of "fragmentation of adult education research" that "weakens the field" (Rubenson, 2015:134). In a more optimistic reading, one might say that it is rather a springtime proliferation process due to the fact that demand for research is so extensive that it draws interest and expertise from several areas. The ambiguity, if we want, is that the number of products and researchers involved in adult education research is growing, but that is not why there are professionals capable of transforming the educational conditions of the population and its emancipation. The scarcity of researchers in adult education comes from the fact that it is a complete figure that, in addition to knowing the methods of quantitative and qualitative research, also knows the methods of educational work.

At the same time, another feature of the field of research must also be referred to. It has always been dominated by research related mainly to adult 
education policies and systems, even in cases where didactics were the object of research. As is well-known, the impact of public policies on the participation of people in adult education in the OECD countries is strongly minor. The rest is mainly covered by the education and consulting market that has its main financiers in public and private companies (Federighi, 2013:59). Within this territory, large global, national and local training and consulting companies are operating. The quality that distinguishes their research work is in many cases particularly high. Take for example one of the most well-known and most popular researches whose results have been continually improving since 1996. This is the case of the "Career Architect ${ }^{\circledR}$ Development Planner" volume, developed by Robert W. Eichinger and Michael M. Lombardo, probably one of the best and most systematic and extensive studies on building and developing the skills and competencies needed to enhance current job performance and to prepare for future career opportunities. It is a tool produced for individual learners working on their own development; for bosses and managers working on the development of someone who works with or for them, for coaches, mentors, and feedback givers helping others work on their development. The book, in its 900 pages, contains the results of a content analysis of many sources: the major and continuing studies at the Center for Creative Leadership, longterm studies at AT\&T and Sears, studies by Harry Levinson, Daniel Levinson, John Kotter, John Gabarro, Eliot Jaques, James Kouzes and Barry Posner, Warren Bennis, Noel Tichy, and Bernard Bass's Handbook of Leadership-a compendium of empirical studies. We have reported this example as "positive" since it is research and authors that have never appeared in the various reviews but have had a great influence by managing researches that have affected millions of adult workers around the world.

Along with this, we remember a further, expanding, and training-related field supporting the generation of innovation processes (not just social) but of product, process, organisational and market. This is an area where other disciplines are trying to answer a growing demand expressed by the production world and by governments.

To handle this process of proliferation and fragmentation it is not enough to respond to the call of Feyerabend when we are invited not to be shy academic rodents who hide their insecurity behind a dark defensive status quo (Hoyningen-Huene, 2000). The real obstacle lies in the fact that much of the research and its results are in usum serenissimi Delphini, i.e. for those who can support it and decide on the use of the results, rarely the subject of scientific publications. This is despite the diffusion of the new distribution systems of research products and Open Source devices.

\section{Concluding notes}

In conclusion, we want to call attention to some points from which depends the type of development that research in the field of adult education needs to face. 


\section{Concentration in the use of results}

There is a strong tendency towards social concentration in the use of educational research results. The added value that people derive from educational research is related to their ability to produce results before they translate into research products, in publications. Access to research is not intended solely in terms of reading products (perhaps executive reports are read). What matters is the ability to inspire goals, to orient the method, to apply solutions. The proliferation processes of educational research are mainly focused on tight bands of people and organisations that can determine their political and applicative goals as well as the choice of models, theories and basic concepts. If even quarks are the product of social engineering processes of science (Pickering: 1984), it is natural that they also act in the field of adult education. This increases the educational distances between the population, enhancing the knowledge, skills and competences of those who benefit from research results and are involved in the decision-making processes that concern them.

Transformative research helps to contain the process of increasing educational and social differences only if new public education is also allowed to access the processes of orientation and management of research itself. The attraction of human and material resources that makes this possible requires structural and financial solutions. A closer relationship between teaching and research in adult education, at least in higher education, could be a first step in this direction.

Access to products

Access to research products is a momentary problem that is plagued by the abundance created by the availability of accessible publications and databases online. However, it does not contain the rich type of product generated by research carried out in favour of structures and actors that direct choices, decisions and actions for private purposes. The products are the property of the customers or are covered by strict confidentiality constraints and kept out of the publishing product market. Only some products can be acquired by buying consulting or research services. The scientific interest in such products does not concern confidential information. The interest of the scientific community is due to the new knowledge gained in identifying the weight of the factors involved in training (e.g. the relationship between financialisation of an organisation and value attributed to human resources, or between international mobility of talents and retention training policies of adult workers), as well as advances in the refinement of methods, techniques and tools for educational research (from the use of art in educational research, the use of interviews, tools for training need analysis, self-assessment techniques).

Other disciplines have large global databases useful for benchmarking and in support of evaluations and choices to be made. This is the case of work psychology with production and continuous evolution of assessment tests or work policies by creating large comparative databases for retention policies. Adult education has not yet achieved these goals. We know that some scholars 
are a bit reluctant to open themselves to the use of artificial intelligence. It is a shame that today it is the only chance to advance knowledge sharing quickly.

The digital divide not only affects some researchers, but the set of adult education participants. A European Parliament report on the accessibility of OER-Open Educational Resources for adult education concludes that: "It is clear that OER can offer many benefits, including, longer term, the possibility of delivering education in a more effective fashion while keeping a close eye on cost. Most of the earlier EU-funded work on OER has focused on either the formal education sectors (universities and schools in particular) or the informal education of already well-educated students. It is timely to extend such work across all educational sectors, including the full spectrum of informal education, and across a wider age range "(Sero Consulting, 2015,11). Without a brave expansion of focus on sharing and open source, research has reduced sharing opportunities and the very teaching products are scarce.

\section{Anticipating the future}

Finally, our society and adult education have a great need for future and hope. Research can help build processes that help to anticipate and prepare to face and direct change in society, workplaces, and private life.

Studies of future demand for adult and continuing education are rare, although some examples show that the subject is meaningful. Let us take, for example, a recent CEPII update on the educational levels of the working-age population over the 1980-2050 period (Fouré, J., 2012). It shows that Europe in 2050 will move quite close to the secondary-school educational levels of the more advanced economies worldwide - though without catching up with them. As far as tertiary education is concerned, current efforts will only serve to maintain current levels of disadvantage.

These data have implications for policy in both tertiary education and adult and continuing education policy (which will be required to fill the gap). The stimulation of research in the sector could help to overcome the difficulty of producing appropriate methods for showing how the educational composition of the adult population changes as a result of specific school enrollment rates.

Forecasting studies are used for understanding the processes of developing human capital over the long-to-medium term. However, the short and medium term also needs to be taken into consideration" (Federighi, 2013).

This is a sector scarcely covered by research. It is important because it indicates the direction that public and private policies might take and because it addresses our capacity to reinvent the future.

\section{References}

Bélanger, P., Blais, M. (1999), World Perspectives in Adult Education Research: Report of the Montreal, in: Mauch, W., Report on the International Seminar on World Trends in Adult Education Research, Montreal, Canada, September 06-09, 1994, Hamburg, 
Unesco Institute for Education, pp. 273-279

Bernstein, B. (1970). Education can not compensate for society. In: New Society, 15(387), p. 344-47.

Biesta, G., (2007). Why 'what works' will not work: evidence-based practice and the democratic deficit in educational research, in: Educational Theory, Vol. 57, University of Illinois, pp 1-22

Bourdieu, P. (1984). Homo Academicus. Stanford, CA, Stanford University Press.

Bourdieu, P. and Passeron, JC (1977), Reproduction in Education, Society and Culture, Beverly Hills, Sage.

Cohen, L., Manion, L., Morrison, K. (2007), Research Methods in Education, Sixth edition , Oxon-New York, Routledge

De Sanctis, F.M. (1988), Verso un 2000 educativo. Adult education project in Prato, Prato, University of Florence-Municipality of Prato

Eichinger, R.W., Lombardo, M.M. (1996), Career Architect $\AA^{\circledR}$ Development Planner, Lominger

Federighi, P. (2013), Adult and continuing education in Europe. Pathways for a skill growthgovernance, Luxemburg, Europen Commission

Fejes, A. \& Nylander, E. (2014). How pluralistic is the research field on adult education? Dominating bibliometrical trends, 2005- 2012, in: European Journal for Research on the Education and Learning of Adults, Vol. 6, No.2, 2015, pp. 103-123

Feyerabend, P.K.(1975), Against Method, New York, NY: New Left Books

Fouré, J., Bénassy-Quéré, A., Fontagné, L. (2012), The Great Shift: Macroeconomic Projections for the World Economy at the 2050 Horizon, CEPII Working paper 201203. Available at http://www.cepii.fr/anglaisgraph/bdd/baseline.htm, also in The CEPII Newsletter, $\mathrm{N}^{\circ} 49,1 \mathrm{Q} 2012$.

Gallino, L. (1993), Scienza, Sociologia della, in: Dizionario di Sociologia, Turin, pp-575-589

Gamow,G. (1998), Biografia della fisica, Mondadori, Milano, 1998, p. 252

Ghadikolaei, E. S., Sajjadi, S.M. (2015), The implications of Feyerabend's epistemological approach for educational research methods, in: Educational Research and Reviews Vol. 10 (17), pp. 2481-2488, 10 September

Godin, B. (2005), Measurement and statistics on science and technology. 1920 to the present, London-New York, Routledge

Habermas, J. (1974) Theory and Practice, trans. J. Viertel. London: Heinemann.

Habermas, J. (1979) Communication and the Evolution of Society. London: Heinemann.

Heisenberg, W.K. (1930, The Physical Principles of Quantum Mechanics, Dover Publications, New York 1930

Heisenberg, W.K. (1958), The Physicist's Conception of Nature, London, Hutchinson

Hoyningen-Huene, P. (2000), Paul K. Feyerabend, in: Preston J, Mune'var G, Lamb D (2000) The worst enemy of science: essays in memory of Paul Feyerabend. Oxford, Oxford University Press.

L'institut canadien d'éducation des adultes, (1999), Overview of Research Trends in Adult Education in Canada, in: Mauch, W., Report on the International Seminar on World Trends in Adult Education Research, Montréal, Canada, September 06-09, 1994, Hamburg, Unesco Institute for Education,, 188-233

Mauch, W. (1999), Report on the International Seminar on World Trends in Adult Education Research, Montréal, Canada, September 06-09, 1994, Hamburg, Unesco Institute for Education,

Maydl, P. (1983), Adult Education in Europe. Methodological Framework for comparative Studies, Prague, Unesco-Ecle 
Pickering, A. (1984), Constructing quarks. A sociological history of particle physics, Chicago

Rubenson, K., Elfert, M. (2015), Adult education research: exploring an increasingly fragmented map, in: European Journal for Research on the Education and Learning of Adults, Vol. 6, No.2, 2015, pp. 125-138

Sero Consulting Ltd, ed. by (2015), Research for cult committee - Adult education and open educational resources, Brussels, European Union 